\title{
PENGARUH PRESENTASE ALKALISASI NaOH TERHADAP KEKUATAN TARIK MATERIAL KOMPOSIT SERAT DAUN NANAS POLYESTER DENGAN METODE VACUUM INFUSION
}

\author{
Mohamad Irkham M. ${ }^{1 *}$, Nur Subeki ${ }^{1}$, Arief Andrian N. ${ }^{2}$ \\ ${ }^{1}$ Dosen Jurusan Teknik Mesin Fakultas Teknik Universitas Muhammadiyah Malang \\ ${ }^{2}$ Alumni Teknik Teknik Mesin Fakultas Teknik Universitas Muhammadiyah Malang \\ Email:*irkham@umm.ac.id
}

\begin{abstract}
Pineapple leaf fiber is currently widely used in furniture and handicraft industries (UKM) because besides being easily available, inexpensive, does not endanger health, can reduce environmental pollution so that later on as a composite reinforcing fiber can overcome environmental problems. From the considerations above, this study aims to determine the effect of the alkalization treatment $(\mathrm{NaOH})$ on the tensile strength test of pineapple leaf fibers by vacuum infusion method and to determine the type of fracture of pineapple leaf fiber composites after tensile testing. Before it is made into a composite of pineapple leaves, it is soaked for 2 hours. Manufacture of composite materials based on ASTM D683-03 standard. From the composite tensile test results obtained the highest average tensile strength in specimens treated with $\mathrm{NaOH} \mathrm{6 \%} \mathrm{which} \mathrm{is} 112 \mathrm{MPa}$. While the lowest at $0 \% \mathrm{NaOH}$ treatment is $68 \mathrm{MPa}$. Composites treated with $\mathrm{NaOH}$ have higher agility than those not treated with $\mathrm{NaOH}$. The highest agility is found in composites with the highest $\mathrm{NaOH}$ treatment.
\end{abstract}

Keywords: Composite, NaOH, Tensile Strength, Pineapple Leaf Fiber

\section{PENDAHULUAN}

Komposit merupakan sejumlah sistem multi fasa sifat gabungan, yaitu gabungan antara bahan matriks atau pengikat dengan penguat[1]. Bahan penguat didapat dari serat. Serat yang digunakan sebagai penguat dalam material komposit dapat berupa serat sintetik atau serat alam[2]. Serat berfungsi sebagai elemen penguat yang menentukan sifat mekanik dari komposit karena meneruskan beban yang diteruskan oleh matrik[3]. Dari penggabungan tersebut akan menghasilkan material komposit yang mempunyai sifat mekanis dan karakteristik yang berbeda dari material pembentuknya, sehingga dapat direncanakan suatu material komposit yang diinginkan. Material komposit merupakan salah satu material yang banyak dimanfaatkan pada saat sekarang ini. Hal Ini dikarenakan komposit memiliki sifat ringan dan relatif kuat. Komposit saat ini masih belum dapat dianggap sepenuhnya biodegradable karena fakta bahwa matriks yang digunakan adalah polimer sintetis yang sumber berbasis minyak bumi [4]. Sehingga penelitian tentang komposit berbahan serat perlu untuk terus dikembangkan.

Dalam kehidupan sehari-hari penggunaan komposit semakin berkembang. Penerapannya tidak terbatas pada bidang otomotif, industri pesawat terbang, dan indusri kapal laut saja, namun sekarang penggunaan komposit telah merambah ke bidang lainnya seperti industri alat olah raga, industri elektronik dan industri peralatan rumah tangga. Hal tersebut disebabkan karena perbandingan antara kekuatan dan berat dari komposit yang baik dibandingkan dengan material logam[5].

Industri banyak menggunakan serat tanaman untuk berbagai aplikasi dari banyak sumber. Di tengah abad ke-20, serat sintetis naik secara drastis, dan industri serat alami meruntuhkan pangsa pasarnya. Serat daun nanas saat ini banyak digunakan dalam industri - industri mebel dan kerajinan rumah tangga (UKM) karena selain mudah didapat, murah, tidak membahayakan kesehatan, dapat mengurangi polusi lingkungan sehingga nantinya dengan pemanfaatan sebagai serat penguat komposit mampu mengatasi permasalahan lingkungan[6]. Serat daun nanas berlimpah jumlahnya untuk keperluan industri, murah, mudah didapat, kekuatan dan kekakuan spesifik tinggi, seat daun nanas ini memiliki kepadatan dan gaya tarik antar molekul yang baik[7]. Proses pembuatan komposit bermacam-macam, tetapi dalam penelitian ini adalah proses Vacuum Assisted Resin Injection ( VARI). VARI memiliki keunggulan dalam hal 
pencapaian, target perancangan komposit polimer, tingkat fraksi volume serat dan fraksi volume void[8]. Tingkat alkaliasi dikontrol oleh kekuatan larutan alkali, tipe alkali, panjang tahap reaksi, dan suhu proses[9].

Tujuan dari penelitian ini adalah untuk memaparkan pengaruh presentase alkalisasi $\mathrm{NaOH}$ serat daun nanas terhadap kekuatan tarik material komposit serat daun nanas polyester dengan metode vacuum infusion yang diharapkan bisa menjadi bahan alternatif dikemudian hari. Dengan perlakuan $\mathrm{NaOH}$ ini diharapkan material komposit dapat menghasilkan sifat-sifat baru yang memiliki keunggulan dari material penyusunnya untuk menghasilkan material yang baru dan juga untuk mengetahui kekuatan tarik dari komposit serta bentuk patahan setelah dilakukan pengujian tarik.

\section{METODOLOGI PENELITIAN}

Dalam penelitian ini alat-alat yang digunakan adalah sebagai berikut : Alat Uji Tarik, Mesin Uji Tarik Serat Tunggal,Release Agent, Mesh, Cetakan, Timbangan Digital, Sealant Tape, Plastic Bag, Vacuum Compressor, Resin Trap, Kaca. Alat bantu lain yang digunakan meliputi :penggaris, sarung tangan,penjepit klem, gelas sikat kawat, dan selang.

Bahan-bahan yang digunakan dalam penelitian tersebut meliputi : Serat daun nanas, Resin dan Katalis, dan Alkali $(\mathrm{NaOH})$.

\section{Prosedur Penelitian}

\section{Pengambilan sampel uji}

Untuk sampel uji serat daun nanas diambil dari wilayah yang sama, dengan usia tanam sekitar 5 - 6 bulan dan dipilih yang mempunyai panjang relatif sama $\pm 100 \mathrm{~cm}$ seperti terlihat pada Gambar 1.

Serat daun nanas yang akan dijadikan sampel serat diambil dari pangkal bawah ke atas sampai dengan panjang sekitar $60 \mathrm{~cm}$

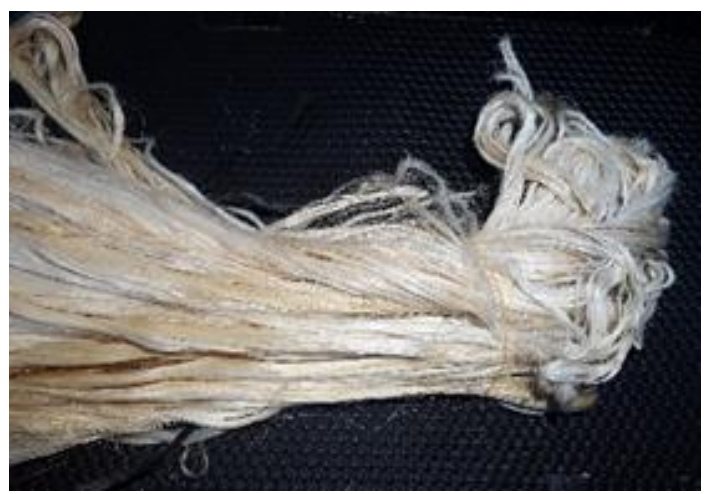

Gambar 1. Serat Daun Nanas

\section{Proses Pemisahan serat}

Setelah mendapat daun nanas yang sesuai maka proses selanjutnya adalah pemisahan serat dilakukan secara mekanis yaitu dengan menyerat serat yang sudah jadi pada papan kayu yang sudah diberi paku sejajar secara berulang-ulang dan dilakukan sampai serat daun nanas terlepas dari jaringan ikatnya. Proes selanjutnya serat direndam dalam larutan $\mathrm{NaOH}$. Serat daun nanas selanjutnya diambil dan dibersihkan lalu dibiarkan kering angin, selanjutnya dilakukan pengamatan dan pengujian tarik.

\section{Proses Perlakuan Alkali}

Perawatan alkali adalah proses kimia yang banyak digunakan untuk menghilangkan komponen hemiselulosa dan lignin dari alam [10].Proses perlakuan alkali dilakukan dengan cara merendam serat daun nanas didalam wadah yang telah diisi larutan alkali $(\mathrm{NaOH})$ dengan variasi konsentrasi $3 \%$; $6 \%$; dan $9 \%$ dan lama perendaman masing-masing konsentrasi selama 2 jam seperti pada gambar 2. Setelah 2 jam, serat diangkat untuk dibilas dengan larutan aquades, lalu dikering-anginkan dan didiamkan pada suhu ruangan sampai diberi tindakan selanjutnya.

\section{Proses Vacuum Infusion Resin}

Kompresor diafragma dan cetakan kaku akrilik merupakan bahan utama dari Proses Vacuum Infusion resin ini dengan komponen pendukung seperti selang infuse diameter dalam 6 $\mathrm{mm}$, resin trap (volume $500 \mathrm{ml}$ dilengkapi vacuum gauge $76 \mathrm{mmHg}$ ) sealant tape dari bahan karet alam, kaca, dan bagging film untuk plastik penutup cetakan.Tahapannya adalah menyiapkan alat dan bahan serta serat daun nanas yang akan digunakan. Mengoleskan release agent pada cetakan kaku akrilik dan pada kaca sebagai alas agar memudahkan saat melepas komposit dari cetakan kaku akrilik setelah selesai pengujian. Memasang sealant tape pada pinggiran seluruh cetakan lalu potong mesh dan pasang plastic bag sampai menutupi cetakan keseluruhan. Selanjutnya memasang sealant tape mengitari sekeliling plastic bag yang direkatkan pada kaca sebagai alas cetakan.Selanjutnya memasang selang dari kedua ujung komposit sebagai jalan untuk resin dan jalan penghisap udara dari alat resin trap. Menghubungkan resin trap dengan mesin vacuum sebagai alat penghisapnya. Selanjutnya menyalakan mesin vacuum dan lakukan pengerjaan sesuai dengan kebutuhan agar mendapatkan hasil yang sesuai. 


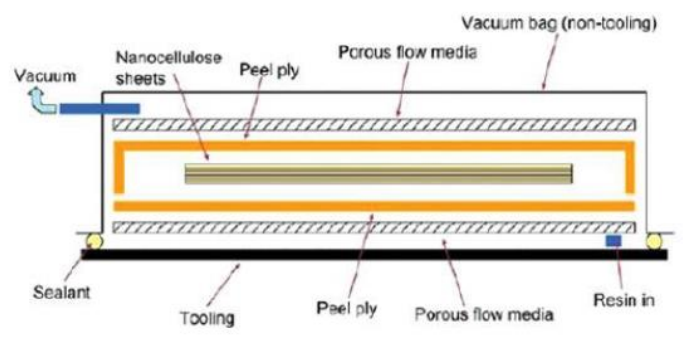

Gambar 2. Sistematika Proses Vacuum Infusion

\section{Pengujian Tarik Komposit Serat Daun Nanas}

Penelitian dan pengambilan data ini dilakukan di laboratorium pengujian bahan Universitas Brawijaya. Tahap akhir yang dilakukan adalah melakukan pengujian dan persiapannya adalah menyiapkan alat pengujian yaitu menggunakan mesin uji tarik. Untuk standart spesimen yang dipilih yaitu ASTM D683-03, Standart Metode Uji Standar untuk menentukan kekuatan tarik yang jelas dari Spesimen Komposit Serat daun nanas.

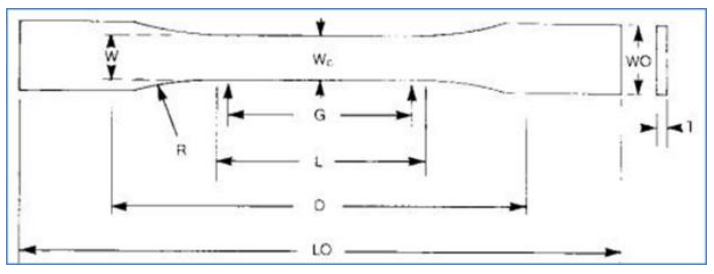

Gambar 3. Spesimen Uji Tarik sesuai ASTM D683-03

Alat uji tarik yang digunakan dapat dilihat pada gambar 4, dimana beban yang digunakan harus sesuai dengan prosedur pengujian yang telah ditentukan.

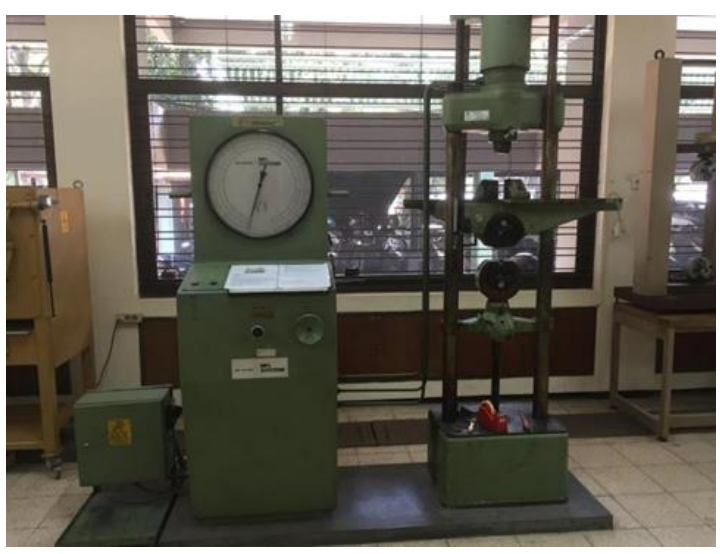

Gambar 4. Mesin Uji Tarik

\section{HASIL DAN PEMBAHASAN \\ Hasil Pembuatan Komposit}

Proses pembuatan komposit serat daun nanas dilakukan dengan metode vacuum infusion dengan variasi perlakuan alkalinisasi. Komposit dibuat mengacu pada standart ASTM D 683-03 untuk pengujian tarik ini

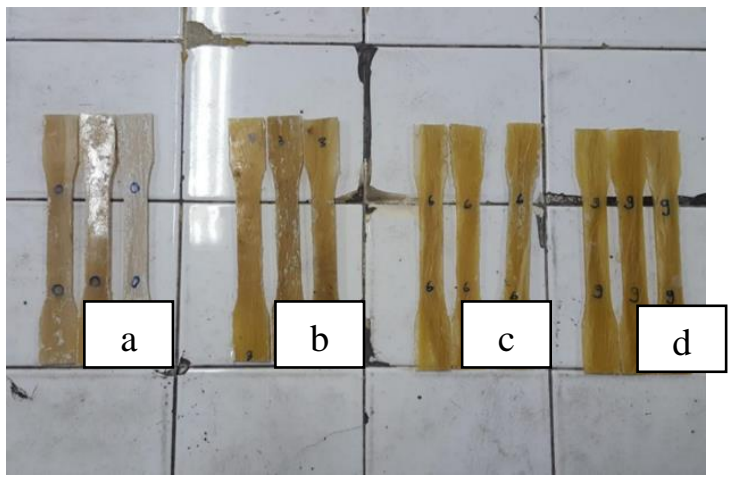

Gambar 5. Spesimen Uji Tarik (a) Tanpa Perlakuan Alkali, (b) Perlakuan Alkali 3\%, (c) Perlakuan Alkali 6\%, (d) Perlakuan Alkali 9\%.

\section{Hasil Uji Tarik}

Dalam pengujian tarik ini didapatkan besarnya tegangan yang merupakan hasil dari pembagian gaya tiap luasan penampang. Dan didapatkan juga nilai regangan untuk membandingan pertambahan panjang yang terjadi dengan panjang awal bahan.

Tabel 1. Data hasil kekuatan tarik komposit

\begin{tabular}{|c|c|c|c|}
\hline NO & $\begin{array}{l}\text { PROSENTASE } \\
\text { NaOH (\%) }\end{array}$ & $\begin{array}{l}\text { KEKUATAN } \\
\text { TARIK (MPa) }\end{array}$ & REGANGAN \\
\hline 1 & 0 & 68 & 1,9 \\
\hline 2 & 3 & 73 & 1,91 \\
\hline 3 & 6 & 112 & 4 \\
\hline 4 & 9 & 91 & 2,4 \\
\hline
\end{tabular}

Pada hasil penelitian menunjukan bahwa semakin tinggi presentase resin atau matriks maka kekuatan tarik mengalami kenaikan. Peningkatan kekuatan tarik komposit dipengaruhi oleh daya ikat antara serat dan matriks yang sempurna serta orientasi serat yang baik. Serat yang mempunyai orientasi serat searah jauh lebih baik daripada komposit orientasi serat acak karena ketika komposit diberikan gaya tarik maka matriks akan dapat menahan gaya tersebut dan diteruskan oleh serat sebelum akhirnya komposit tersebut akan putus atau patah[11]. 


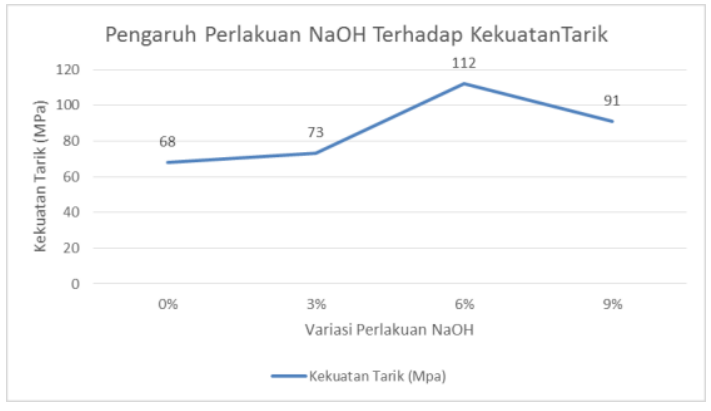

Gambar 6. Grafik Pengaruh NaOH Terhadap tegangan tarik

Dari gambar 6 terlihat bahwa kekuatan tarik semakin meningkat hingga prosentase $\mathrm{NaOH}$ sebesar 6\%. Namun akan menurun setelah prosentase semakin ditambah. Tegangan tarik ini dipengaruhi oleh besarnya prosentase alkalisasi $\mathrm{NaOH}$, yang mana pada prosentase $6 \%$ besarnya tegangan tarik masih lebih besar dibandingkan pada perlakuan alkali 3\%, 9\%, bahkan yang tanpa perlakuan alkalisasi. Peningkatan kekuatan tarik serat setelah mengalami perlakuan alkali $(\mathrm{NaOH})$ terjadi karena adanya peningkatan kekakuan serat. Kekakuan serat meningkat karena peningkatan kandungan selulosa dan berkurangnya kandungan unsur lain seperti hemiselulosa, lignin, dll.[12]

Pada perlakuan yang tanpa alkalisasi, maka ikatan yang terjadi tidaklah kuat, karena pada serat terdapat lapisan lilin atau lignin. Hal ini yang menyebabkan terjadinya tegangan geser di permukaan serat yang disebut pullout. Pullout adalah ikatan matrik dan serat tidak kuat, sehingga mengakibatkan serat terlepas dari matrik[13]. Hal ini menyebabkan besarnya tegangan dan regangan juga menjadi rendah.

Pada perlakuan alkalisasi $\mathrm{NaOH} 9 \%$, hemiselulosa, lignin, dan pektin justru semakin hilang yang menyebabkan tegangan tarik justru semakin menurun. Hal ini menyebabkan kumpulan microfibril sebagai penyusun serat yang disatukan oleh lignin dan pektin akan terpisah[14].

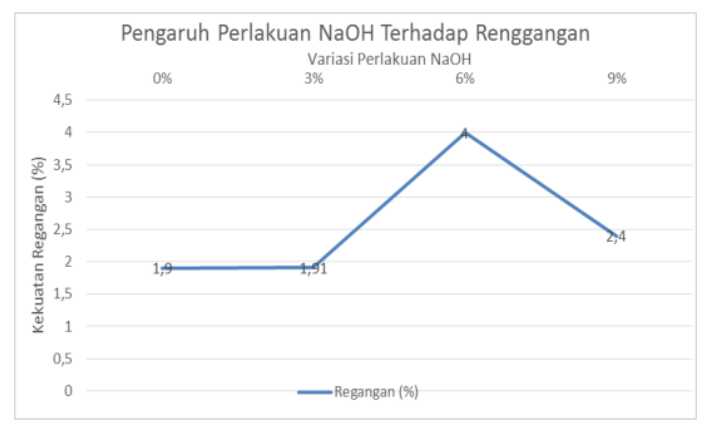

Gambar 7. Grafik Pengaruh $\mathrm{NaOH}$ terhadap regangan

Berdasarkan gambar 7 diatas, trend grafik regangan meningkat seiring peningkatan prosentase $\mathrm{NaOH}$. Namun, peningkatan regangan tersebut hanya sampai pada prosentase $6 \%$, kemudian turun pada prosentase $\mathrm{NaOH} 9 \%$ penambahan prosentase $\mathrm{NaOH}$. Regangan meningkat akibat dari reaksi perbandingan komposit kepada beban tarik yang diterima menyebabkan komposit mengalami tegangan dan terjadi regangan sebagai pergeseran internal ditingkat pada atom partikel yang menyusun komposit maka dari itu komposit mengalami pertambahan panjang. Dalam hal ini berakibat pada nilai dari regangan komposit ketika dibandingkan dengan panjang (gauge length). Semakin tinggi dari nilai pertambahan panjang $(\Delta \mathrm{L})$ maka regangan akan bertambah tinggi juga.

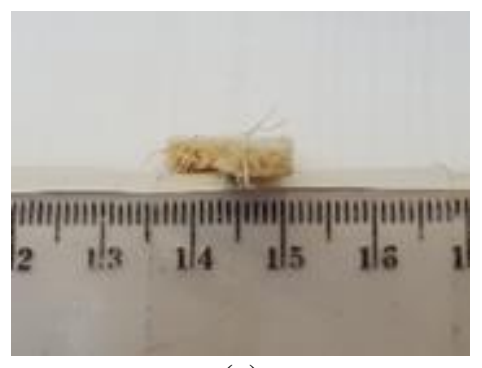

(a)

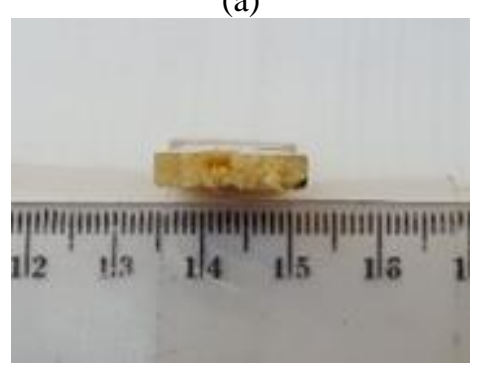

(b)

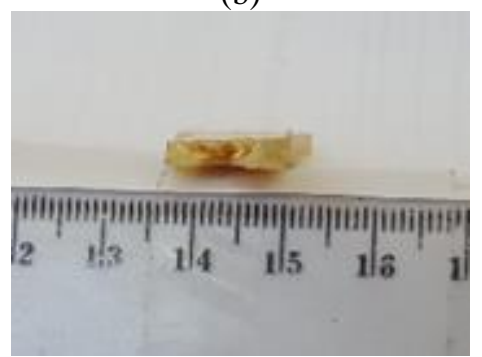

(c)

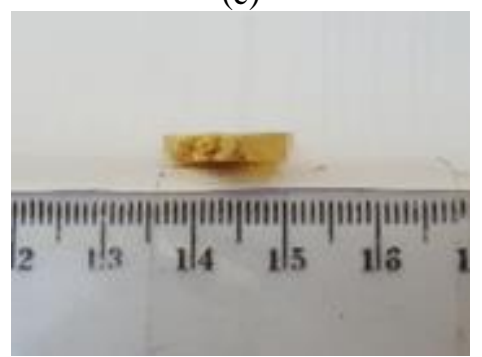

(d)

Gambar 8. Bentuk Patahan (a) Tanpa Perlakuan Alkali, (b) Perlakuan Alkali 3\%, (c) Perlakuan Alkali 6\%, (d) Perlakuan Alkali 9\%.

Berdasarkan gambar 8 dapat dilihat bahwa dengan bertambahnya prosentase $\mathrm{NaOH}$ yang 
diberikan saat perendaman maka hasil patahan menjadi semakin getas.

Hal ini sesuai dengan besarnya kekuatan tarik yang terjadi dimana justru kekuatan tarik yang terbesar terjadi pada prosentase alkalisasi $\mathrm{NaOH}$ sebesar 6\%. Dari seluruh bentuk patahan yang terjadi tidak ada yang mengalami pull out, hal ini disebabkan dengan penggunaan metode vacuum infusion ikatan antara maktriks dan serat dapat terbentuk dengan baik. Sehingga tidak ada serat yang terlepas dari matriks.

\section{KESIMPULAN}

Dari hasil penelitian yang dilakukan maka dapat disimpulkan beberapa hal yaitu pengujian kekuatan tarik produk komposit dengan metode vacuum infusion tertinggi terdapat pada komposit serat daun nanas dengan perlakuan $\mathrm{NaOH} 6 \%$ yaitu sebesar $112 \mathrm{MPa}$, perlakuan $\mathrm{NaOH} 9 \%$ sebesar $91 \mathrm{MPa}$, perlakuan $\mathrm{NaOH} 3 \%$ sebesar 73 $\mathrm{MPa}$, perlakuan $\mathrm{NaOH} \quad 0 \%$ sebesar 68 MPa.Pengaruh perendaman $\mathrm{NaOH}$ dari variasi $0 \%, 3 \%, 6 \%, 9 \%$ dan penggunaan metode vacuum infusion menyebabkan seluruh bentuk patahan yang terjadi termasuk dalam bentuk patahan getas.

\section{SARAN}

Dari hasil penelitian yang dilakukan bahwa kekuatan tarik dari material komposit sangat dipengaruhi oleh perlakuan pada serat. Pada pengujian ini masih menggunakan variasi prosentase alkalisasi $\mathrm{NaOH}$ saja, sehingga masih sangat mungkin dilakukan penelitian lanjutan untuk meneliti dengan memberikan perlakuan yang lain, baik itu perlakuan pemanasan awal, orientasi serat, maupun perlakuan pada matriknya itu sendiri.

\section{DAFTAR PUSTAKA}

[1] M. Muhajir, M. A. Mizar, D. A. Sudjimat, and J. P. T. Mesin-ft, "ANALISIS KEKUATAN TARIK BAHAN KOMPOSIT MATRIKS RESIN," no. 2, pp. 1-8, 2016.

[2] D. Indonesia, "Pengaruh Fraksi Volume Serat dan Lama Perendaman Alkali terhadap Kekuatan Impak Komposit Serat ArenPolyester," vol. 14, no. 1, pp. 26-32, 2011.

[3] M. Septiana, P. Sinuhaji, and M. Syukur, "PEMBUATAN DAN KARAKTERISASI KOMPOSIT SERAT PALEM SARAY DENGAN MATRIKS POLIESTER," no. 1, 2003.

[4] D. B. Mathivanan, J. P. Siregar, M. Ruzaimi, M. Rejab, and D. Bachtiar, "The Mechanical
Properties of Alkaline Treated Pineapple Leaf Fibre to Reinforce Tapioca based Bioplastic Resin Composite."

[5] K. Anam, A. Purnowidodo, and A. Octaridwan, "Pengaruh Variasi Fraksi Volume Serat Daun Nanas dan Ukuran Cetakan terhadap Prosentase Penyusutan Komposit Matriks Polyester dengan Cetakan Silikon," no. Snttm Xiv, pp. 7-8, 2015.

[6] T. S. Hadi, S. Jokosisworo, and P. Manik, "ALTERNATIF BAHAN KOMPOSIT PEMBUATAN KULIT KAPAL DITINJAU DARI KEKUATAN TARIK , BENDING DAN IMPACT," vol. 4, no. 1, pp. 323-331, 2016.

[7] A. Danladi and J. Shu, "Fabrication and Properties of Pineapple Fibre / High Density Polyethylene Composites," vol. 4, no. 3, pp. 139-143, 2014.

[8] R. Gunawan, "PEMBUATAN MATERIAL KOMPOSIT POLIMER DENGAN METODA VACUUM ASSISTED RESIN INFUSION (VARI)." 2005.

[9] Y. Li, S. Zhu, Y. Feng, F. Xu, J. Ma, and F. Zhong, "Influence of Alkalization Treatment on the Color Quality and the Total Phenolic and Anthocyanin Contents in Cocoa Powder," no. February, 2013.

[10] K. Panyasart, N. Chaiyut, and T. Amornsakchai, "Effect of surface treatment on the properties of pineapple leaf fibers reinforced polyamide 6 composites," Energy Procedia, vol. 56, pp. 406-413, 2014.

[11] J. Fisika and F. Universitas, "PEMBUATAN DAN KARAKTERISASI SIFAT MEKANIK BAHAN KOMPOSIT SERAT DAUN NENASPOLYESTER DITINJAU DARI FRAKSI MASSA DAN ORIENTASI SERAT," vol. 3, no. 1, pp. 30-36, 2014.

[12] K. Witono, Y. S. Irawan, R. Soenoko, and H. Suryanto, "Pengaruh Perlakuan Alkali (NaOH) Terhadap Morfologi Dan Kekuatan Tarik Serat Mendong," Rekayasa Mesin, vol. 4, no. 3, p. pp.227-234, 2013.

[13] I. G. Sudiarsa, T. G. T. Nindhia, and I. W. Surata, "Pengaruh Fraksi Berat Serat Daun Nanas Terhadap Kekuatan Tarik Dan Lentur Komposit Polyester," J. Ilm. Tek. Desain Mek., vol. 7, no. 2, pp. 109-114, 2018.

[14]R. Marcelino, "the Mechanical Characteristics of Composites Coconut Fibers With the Variation of Direction of the Fiber Science and Technology Faculty," 2018. 